\title{
Microstructure Evolution of AA7050 Al Alloy During Equal-Channel Angular Pressing
}

\author{
Katia Regina Cardoso ${ }^{\text {a*, }}$, Dilermando Nagle Travessa,
}

Alberto Moreira Jorge Jr. ${ }^{\mathrm{b}}$, Walter José Botta ${ }^{\mathrm{b}}$

\author{
àDepartamento de Ciência e Tecnologia, Universidade Federal de São Paulo - UNIFESP, \\ Rua Talim, 330, CEP 12231-280, São José dos Campos, SP, Brasil \\ ${ }^{\mathrm{b}}$ Departamento de Engenharia de Materiais - UFSCar, Rod. Washington Luís, SP-310, \\ Km 235, CEP 13565-90, São Carlos, SP, Brasil
}

Received: December 2, 2011; Revised: February 28, 2012

\begin{abstract}
High strength AA7050 aluminum alloy was processed by ECAP through route A in the T7451 condition. Samples were processed at $423 \mathrm{~K}$, with 1 and 3 passes. The resulting microstructure was evaluated by optical microscopy (OM), scanning electron microscopy (SEM) and transmission electron microscopy (TEM). The phases were identified by X-ray diffraction (XRD) using monochromatic $\mathrm{Cu} \mathrm{K} \alpha$ radiation. Rockwell $\mathrm{B}$ hardness and tensile tests were performed for assessment of mechanical properties. The microstructure was refined by the formation of deformation bands, with dislocation cells and elongated subgrains, with an average width of $240 \mathrm{~nm}$, inside these bands. The number of deformation bands increased with the number of passes. A reduction of precipitates size was observed with increase in the number of passes, when compared to initial condition, probably resulting from particle fragmentation during ECAP. After three passes the precipitates tend to a more equiaxed morphology and have sizes smaller than $10 \mathrm{~nm}$. Phases $\eta$ ' and $\eta$ coexist in the microstructure, but $\eta$ is the dominant phase, mainly after three passes. The hardness of alloy after the first pass of ECAP is almost equal to the initial condition. After three passes the hardness showed a slight reduction which must be result from recovery process. There was a slight improvement in the yield strength and elongation after one pass, when compared to the initial T7451 condition. The improvement in the ultimate tensile strength was less significant.
\end{abstract}

Keywords: severe plastic deformation, ECAP, aluminum alloy

\section{Introduction}

Severe plastic deformation by Equal Channel Angular Pressing (ECAP) is one of the processing methods currently used to greatly refine microstructure and enhance mechanical behavior with higher strength and good ductility ${ }^{1-3}$. ECAP is especially attractive because it is the most cost effective and easiest to perform among the processes that result in nanostructured materials due to the simplicity of the process and tooling.

ECAP allows the metals to undergo severe shearing deformation, breaking the original texture into ultrafine or nanostructured material after a number of passes. The process imposes a high strain on the sample, introducing a high density of dislocations, which are re-arranged during the multiple passes of ECAP to form subgrains and subsequently new high-angle grain boundaries s, $^{1,2,4-6}$.

Aluminum and its alloys can be considered as the most suitable material for ECAP process ${ }^{7-9}$. However, the age-hardenable alloys are generally difficult to process at room temperature because they normally fail by catastrophic cracking or segmentation ${ }^{10}$. This behavior results from the formation of precipitates in the solution treated $\mathrm{Al}$ alloys that leads to loss of deformability of the material. These problems may be avoided by increasing the processing

*e-mail: krcardoso@unifesp.br temperature ${ }^{11,12}$, which however, can also bring additional problems such as a larger grain size and additional precipitation, leading to overaging of the material.

Despite this difficulty, as the age-hardenable $\mathrm{Al}$ alloys are of high performance in aerospace applications, there is a growing interest in process these alloys by ECAP and combining the nanocrystalline microstructure with a good control of the precipitation hardening ${ }^{11,13-16}$. Recently, Chinh et al..$^{10}$ developed a strategy for processing these alloys by ECAP at room temperature and found that the pressing may be conducted successfully, without the formation of catastrophic cracking or segmentation, if performed immediately after quenching from the solution treatment temperature or at least within a very short pre-aging time ${ }^{12,17}$. Other authors have processed these alloys in the over aged condition $^{18}$.

Besides the difficulty in processing, ECAP has also a complicated effect on the precipitation microstructure of age-hardenable $\mathrm{Al}$ alloys. It has been reported that at room temperature, ECAP generally suppresses precipitation in as-quenched samples ${ }^{15}$ and can cause dissolution and fragmentation of pre-existing phases ${ }^{19}$. ECAP can also affect the precipitation sequence and even suppresses certain phases during subsequent heat treatment ${ }^{20}$. On 
the other hand, ECAP at elevated temperature promotes the precipitation, changes the precipitation kinetics and changes the morphology of precipitates ${ }^{11,15,21}$. Xu et al. ${ }^{21,22}$ have demonstrated that the very high stresses imposed on an A17034 alloy by ECAP at $473 \mathrm{~K}$, are effective in leading to a fragmentation of the rod-like $\mathrm{MgZn}_{2}$ precipitates and produce an uniform distribution of fine spherical precipitates. This precipitate microstructure favors the structural stability even at high temperatures as $673 \mathrm{~K}^{21-23}$.

AA7050 aluminum alloy is a high strength $\mathrm{Al}-\mathrm{Zn}-\mathrm{Mg}-\mathrm{Cu}$ alloy with a high content of alloying elements. This alloy is optimized to have a good response during artificial ageing by the precipitation of $\eta$ ' and $\eta \mathrm{MgZn}_{2}$ phases resulting in a more common commercial condition (T7). In this condition the material presents a good combination of strength and stress corrosion resistance ${ }^{24}$. Although little information is available in literature concerning the effects of ECAP in this alloy ${ }^{25,26}$, it is supposed that additional strengthening could be obtained as result from the different hardening mechanisms that usually takes place during ECAP, as solid solution, grain refinement, dislocation strengthening and precipitation strengthening. The effect of these mechanisms depends on initial condition of alloy. In a previous work ${ }^{27}$ ECAP performed in the as quenched condition resulted in significant strength improvement compared to the alloy in the commercial overaged condition, due the grain size refining and intense precipitation during ECAP.

This work aims to investigate the effects of ECAP on the microstructural evolution of the high strength AA7050 aluminum alloy in the commercial overaged condition T7451. The pressings were performed at $423 \mathrm{~K}$ by route A. The influence of ECAP on the grain structure, precipitation state and mechanical properties are discussed in order to contribute to a better understanding of the behavior of high strength $\mathrm{Al}-\mathrm{Zn}-\mathrm{Mg}-\mathrm{Cu}$ alloys during ECAP.

\section{Experimental Procedures}

AA7050 aluminum alloy, with nominal composition shown in Table $1^{[28]}$, was received as a plate in the condition T7451. Prior to ECAP, short billets were machined from the plate, with a length of $90 \mathrm{~mm}$ (parallel to the rolling direction of the plate) and a diameter of $10 \mathrm{~mm}$. The billets were processed by ECAP at $423 \mathrm{~K}$, with one and three passes. The heating of die and samples to $423 \mathrm{~K}$ was done using a set of resistances integrated to the die. A thermocouple inserted in the die close to the intersection of the channels controlled the temperature.

The die had an internal angle of $120^{\circ}$ and an additional angle of $60^{\circ}$ at the outer concordance radius, where the two channels intersect each other. This configuration resulted in a theoretically effective strain of approximately 0.6 on each pass, not considering the attrition contribution. The ECAP processing was performed at $0.5 \mathrm{~mm} / \mathrm{s}$ using a 30 tonnes mechanical press and $\mathrm{MoS}_{2}$ as a lubricating media. The pressings were done by route $\mathrm{A}$, in which the sample does not undergo rotation between the passes.

Microstructural characterization of the samples after ECAP was performed by optical microscopy (OM), scanning electron microscopy (SEM) and transmission electron microscopy (TEM). Samples for OM and SEM were prepared by conventional techniques of metallographic preparation. For TEM characterization, thin foils of the material were cut from the cross-section of each billet (perpendicular to the pressing direction). The foils were thinned up to $100 \mu \mathrm{m}$ by conventional grinding. Then, $3 \mathrm{~mm}$ discs were punched from the specimens and subsequently ion-milled in a Gatan Dual Ion Milling System with beam energy of $5 \mathrm{keV}$ under an argon atmosphere. X-ray diffraction (XRD) measurements, using $\mathrm{Cu} \mathrm{K} \alpha$ radiation, were performed in order to identify the alloy phases.

Rockwell B hardness tests were performed on all samples for a preliminary assessment of mechanical properties. Seven measurements were taken from each sample and the average value of five measurements, excluding the highest and lowest values, were recorded. Samples in the initial condition and after one pass of ECAP were subjected to tensile tests. Samples having $4 \mathrm{~mm}$ diameter and $25 \mathrm{~mm}$ length at the thinner gauge section were tested in a universal testing machine with a crosshead speed of $0.5 \mathrm{~mm} / \mathrm{min}$. Three samples of each condition were tested and the average values for yield and ultimate strength, as well as elongation, were recorded. Variance analysis (ANOVA) was used to compare statistical differences among the mean values of hardness and tensile properties of the samples with a confidence interval of $95 \%$.

\section{Results and Discussion}

TEM micrographs of the as received AA7050-T7451 alloy in Figure 1 show a large amount of precipitates with different morphology and sizes. Elongated particles of about $50 \mathrm{~nm}$ are observed at grain boundaries, Figure 1a, while inside the grains most of precipitates are of plate shape with sizes smaller than $20 \mathrm{~nm}$, Figure 1b. Some particles with a needle shape with lengths of about $20 \mathrm{~nm}$ and thickness of about $4 \mathrm{~nm}$ are also observed. The diffraction pattern of selected area (SAD) related to the micrograph of Figure $1 \mathrm{~b}$ was taken with the beam parallel to the zone axis [112]. Multiple spots appear near 1/3 (220) and 2/3 (220) along the $\langle 111\rangle$ direction resulting from metastable $\eta$ ' and variants of $\eta$ phase $\left(\mathrm{MgZn}_{2}\right)$. Other weaker diffraction reflections of $\eta$ ' also are present, as exemplified by spots surrounded by white circles. The diffraction pattern $[\overline{1} 12]$ also shows

Table 1. Nominal Composition of AA7050 aluminum alloy (AMS 4050 specification $^{28}$ ).

\begin{tabular}{|c|c|c|c|c|c|c|c|c|c|c|}
\hline \multirow{2}{*}{$\begin{array}{l}\text { Composition } \\
(\text { wt. }(\%))\end{array}$} & \multicolumn{10}{|c|}{ AA 7050} \\
\hline & Zn & $\mathrm{Cu}$ & Mg & $\mathbf{Z r}$ & $\mathbf{F e}$ & $\mathbf{S i}$ & Mn & $\mathbf{T i}$ & $\mathrm{Cr}$ & $\begin{array}{c}\text { Others } \\
\text { (total) }\end{array}$ \\
\hline Min. & 5.7 & 2.0 & 1.9 & 0.08 & - & - & - & - & - & - \\
\hline Max. & 6.7 & 2.6 & 2.6 & 0.15 & 0.15 & 0.12 & 0.10 & 0.06 & 0.04 & 0.15 \\
\hline
\end{tabular}


a spotted ring pattern around the transmitted beam that has been attributed to the appearance of each variant of the orientation relationship of $\eta$ phase with the matrix ${ }^{29}$.

Figure 2 shows magnified X-ray diffraction pattern of the alloy in the initial condition and after ECAP. The peaks related to precipitates are not well defined and their positions are deviated from the equilibrium $\eta$ phase in the diffraction pattern of alloy in the initial condition, Figure $2 \mathrm{a}$, which seems to confirm the presence of the metastable $\eta$ ' phase in addition to the $\eta$ phase. Figures $2 b$ and $2 c$ show

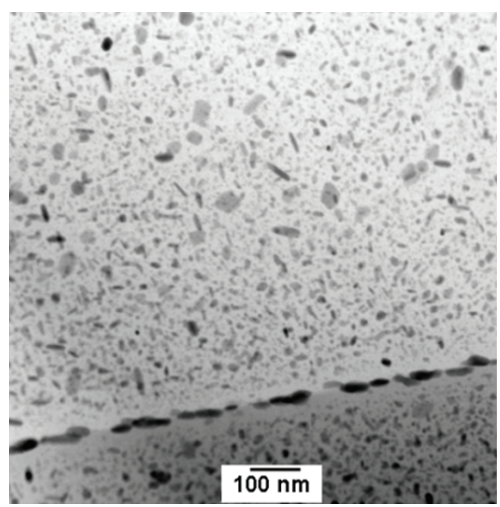

(a)

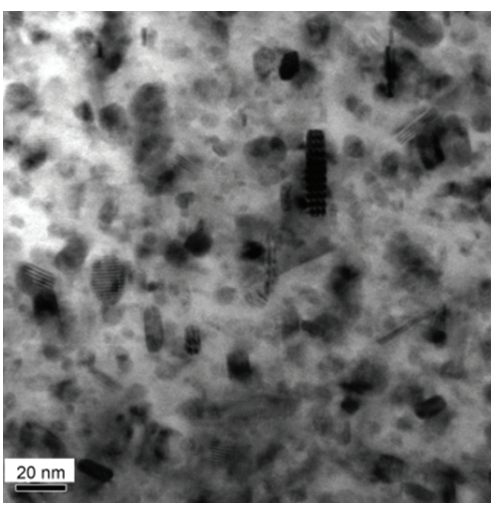

(b)

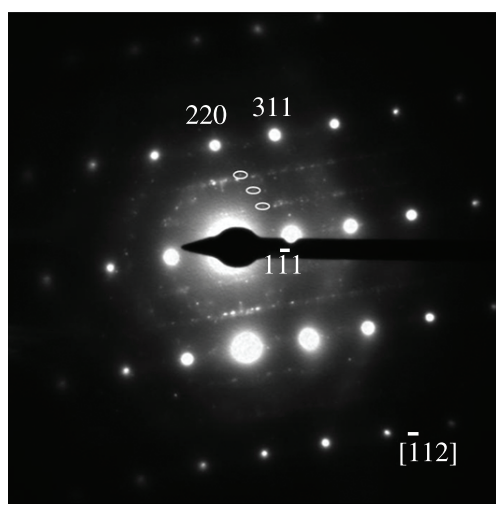

(c)

Figure 1. TEM micrographs of AA7050 alloy in the T7451 a) STEM bright field; b) TEM bright field with corresponding SAD.

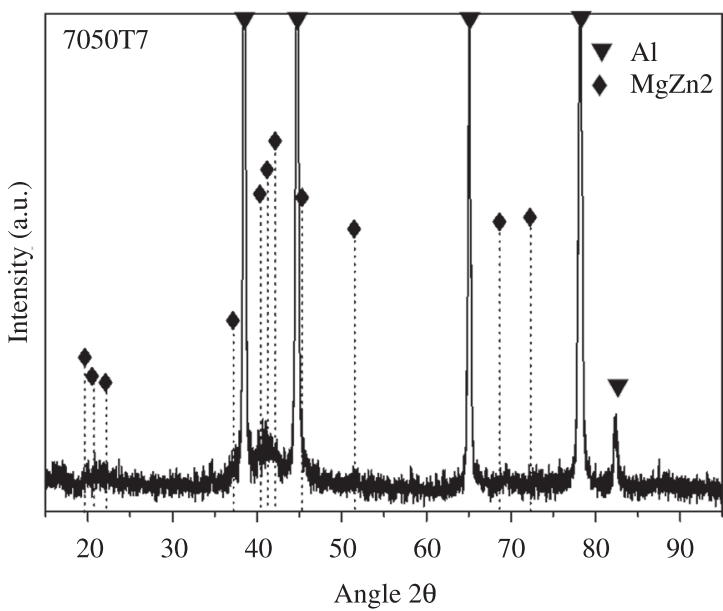

(a)

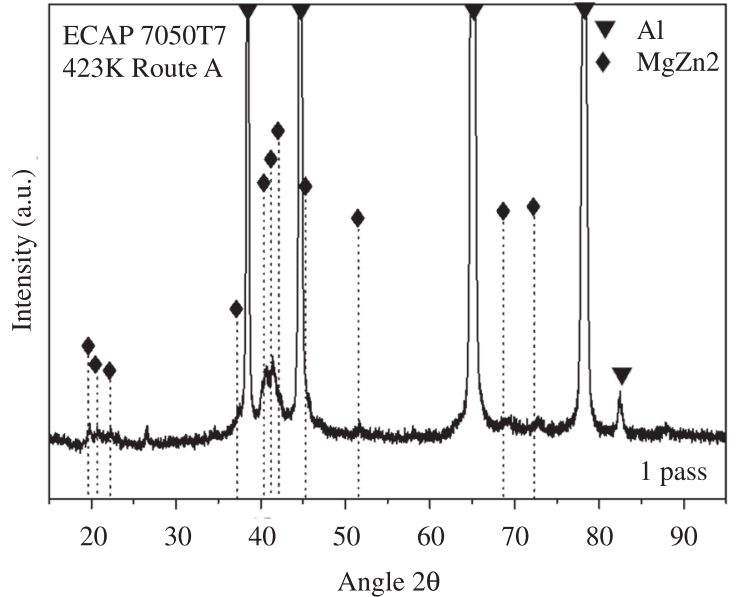

(b)

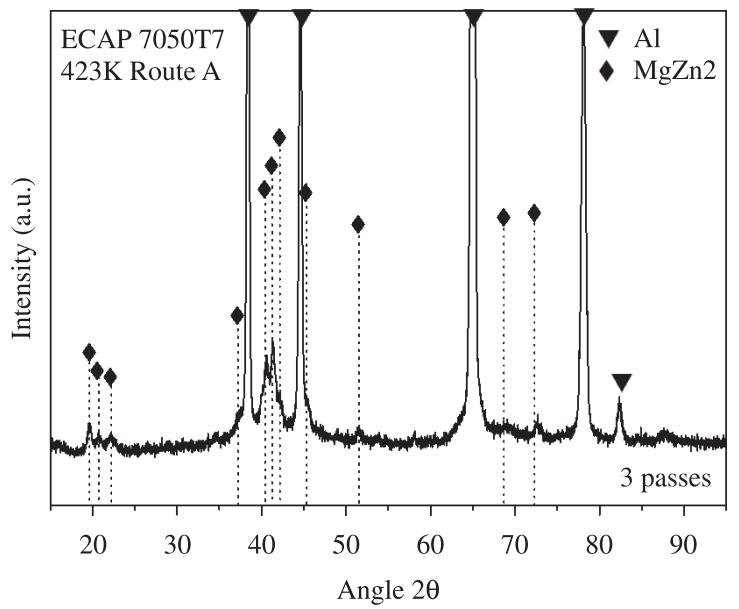

(c)

Figure 2. X-ray patterns for $7050 \mathrm{Al}$ alloy: (a) as-received condition T7451 and; processed by ECAP (b) one pass, (c) three passes. 
the x-ray diffraction patterns taken on the cross-sections of samples after ECAP at $423 \mathrm{~K}$. Peaks from the equilibrium $\eta$ phase were identified after one and three passes. These peaks become more defined and intense with the increase in the number of passes to three indicating that some of the $\eta$ ' phase had transformed into $\eta$ phase during ECAP.

Figure 3 shows optical and SEM micrographs of $7050 \mathrm{Al}$ alloy after ECAP at $423 \mathrm{~K}$. It was observed that after the first pass the microstructure does not undergo appreciable change except for the appearance of deformation bands inside the grains, as showed by SEM micrograph of Figure $3 b$. The increase in the number of passes to three leads to a refinement in the microstructure with grain elongation and increase in the number of deformation bands, Figures $3 \mathrm{c}$ and $3 \mathrm{~d}$.

TEM micrographs of the alloy after ECAP are showed in Figure 4. Elongated subgrains with average width of $240 \mathrm{~nm}$ and high density of dislocations at their boundaries are formed during the processing, Figures $4 \mathrm{a}$ and $4 \mathrm{c}$. A higher amount of dislocations was created and accumulated at subgrain boundaries with the increase in the number of passes to three, Figure 4c. Concerning the precipitation state, ECAP seems to affect the size and morphology of particles. Although no quantitative analysis had been made in this work, observations seem to indicate that after the first pass the precipitates are larger than those at initial condition, which could be result of coarsening of small particles during ECAP at $423 \mathrm{~K}$, Figure 4b. The particle size tends to decrease and the morphology to be more spherical with the increase in the number of passes to three, Figures $4 \mathrm{e}$ and $4 \mathrm{f}$, which should be the result of fragmentation process due to the very high stresses imposed by ECAP. The precipitate fragmentation by ECAP was observed in other 7xxx series alloys $^{20,22}$ and was also reported during equal-channel angular rolling (ECAR) of an AA7050 aluminum alloy ${ }^{30}$. The selected diffraction patterns in Figures $4 \mathrm{~b}$ and $4 d$ show spots scattered randomly that match with a simulated ring pattern of the $\eta$ phase showed superimposed over the SAD pattern in Figure 4b. This result shows that the major phase after ECAP is the $\eta$ phase, what is in agreement with X-ray diffraction results, indicating that the temperature and time of the ECAP processing was sufficiently high to cause the transformation of the metastable $\eta$ ' phase to stable $\eta$ phase.

Table 2 shows the mechanical properties of the alloy after ECAP obtained by Rockwell B hardness and tensile tests. As a reference, the properties of the as received material (temper T7451) are also presented. The sample after three passes was not tested in tension because it already showed signs of cracking during ECAP. The results show a statistically significant increase in hardness after 1 pass

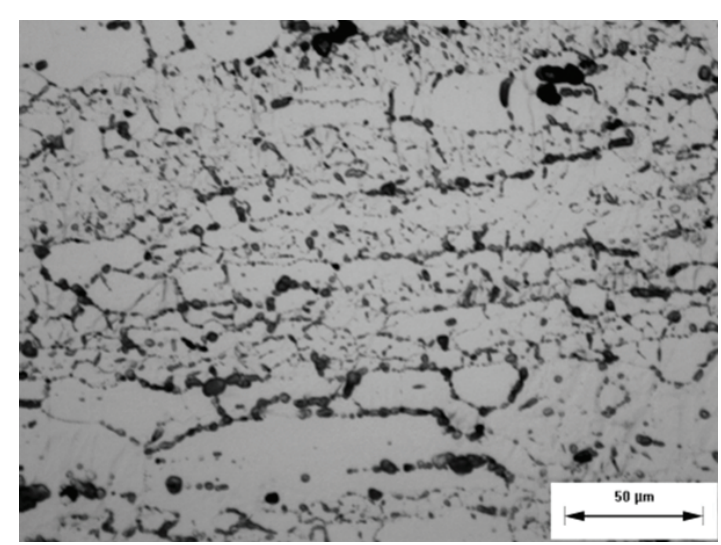

(a)

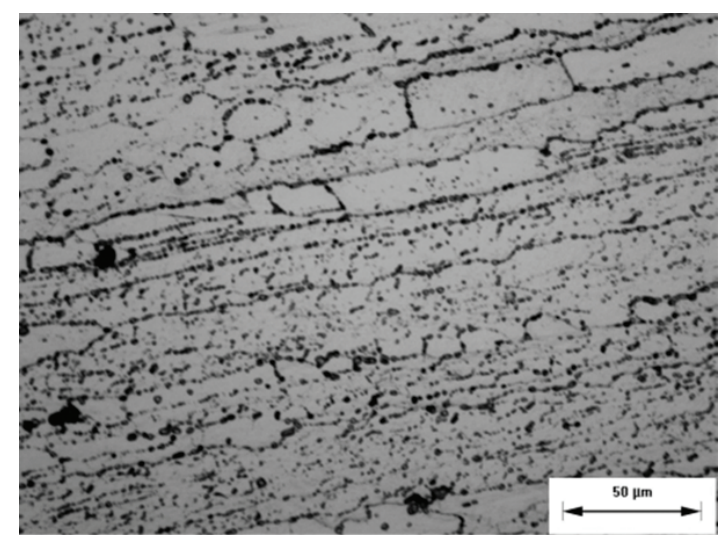

(c)

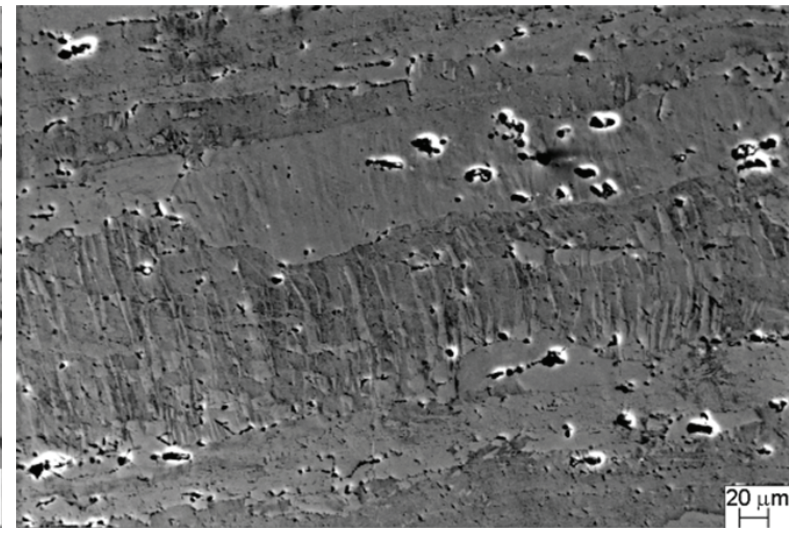

(b)

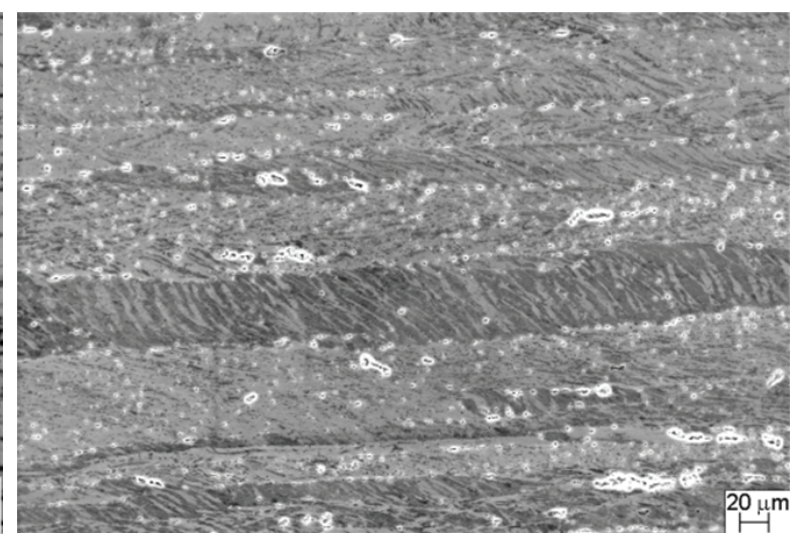

(d)

Figure 3. a) Optical and; b) SEM micrographs of $7050 \mathrm{Al}$ alloy after one pass of ECAP at 423K. c) Optical and; d) SEM micrographs of $7050 \mathrm{Al}$ alloy after three passes of ECAP at $423 \mathrm{~K}$. All the images were obtained from longitudinal section of the cylindrical rods. 


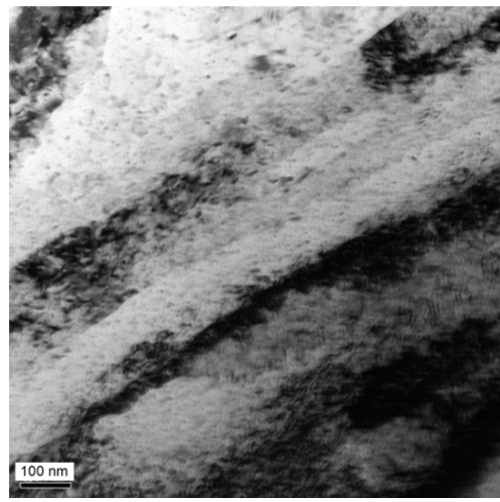

(a)

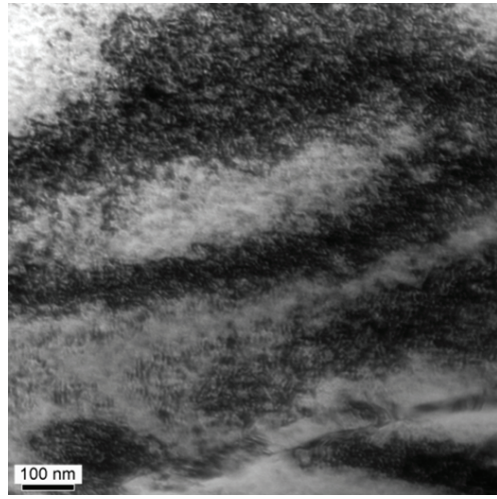

(c)

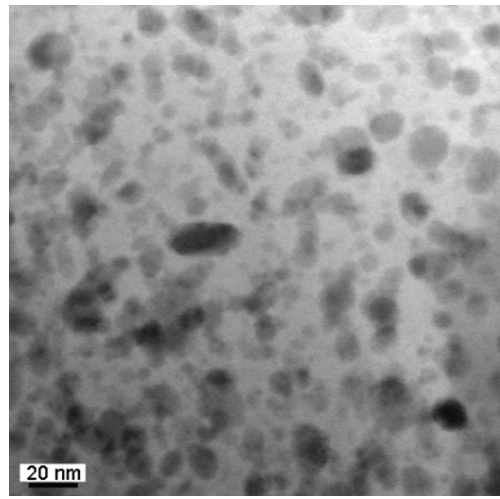

(e)

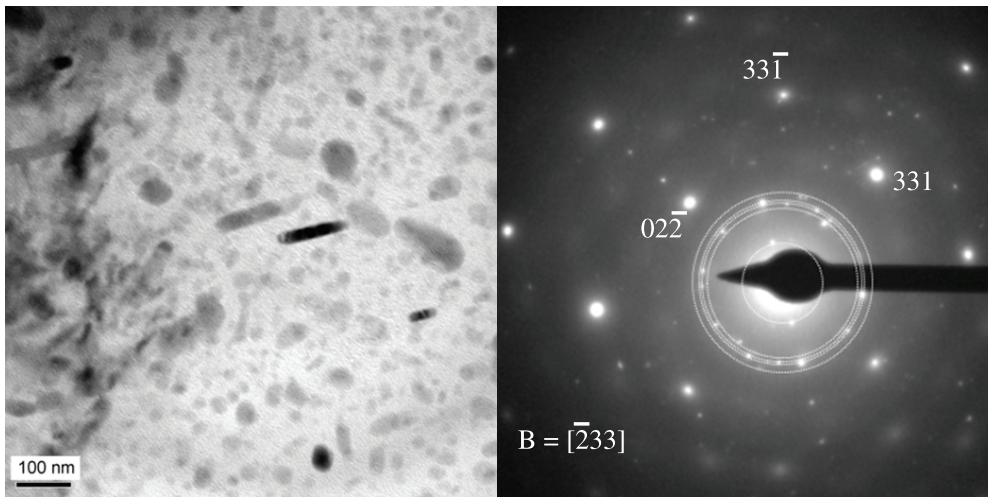

(b)

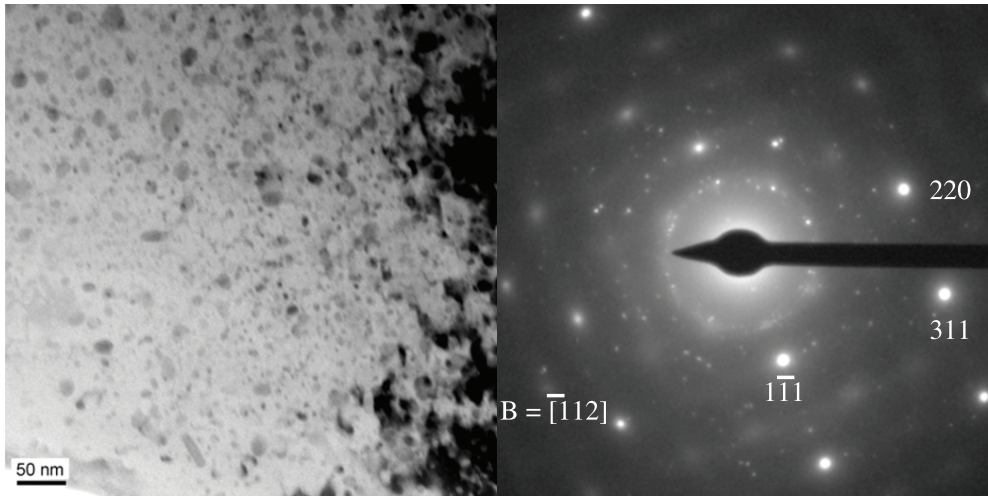

(d)

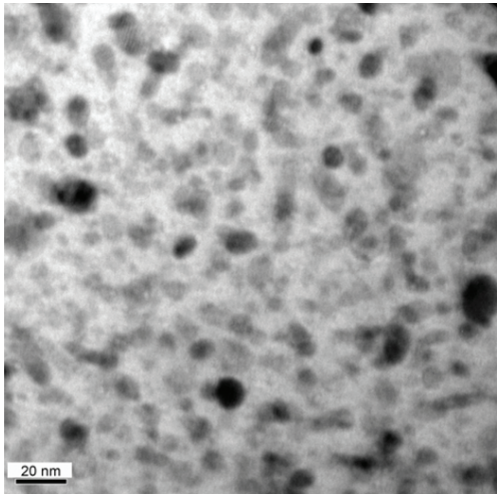

(f)

Figure 4. TEM micrographs of $7050 \mathrm{Al}$ alloy after ECAP at 423K. (a), (b) and (e) one pass; (c), (d) and (f) three passes.

of ECAP $(\mathrm{p}<0.05)$ followed by a significant reduction in this property after three passes $(\mathrm{p}<0.05)$. Although a slight increase could be observed in the average values of ultimate and yield strength of sample after 1 pass of ECAP when compared to the initial T7451 condition, this increase was not statistically significant $(\mathrm{p}>0.05)$. The elongation seems to increase after ECAP $(\mathrm{p}<0.05)$, again in comparison with the initial condition.

The grain refinement by ECAP has been explained ${ }^{1,2,4-6}$ by the increase of dislocation density, formation of a cellular or sub-grain structure and subsequent formation of high angles grain boundaries by partial annihilation of dislocations. Second phase particles, as $\mathrm{Al}_{3} \mathrm{Zr}$, normally present in the AA7050 alloy, can hinder the movement of dislocations and act as dislocation sources which can affect the grain size refinement ${ }^{30}$. Nam et al. ${ }^{30}$ showed that large platelet $\mathrm{MgZn}_{2}$ precipitates can also act as obstacles to dislocations and provide favorable sites for the development of grain boundaries. However, the same authors showed that small spherical particles cannot play the same role. Murayama et al. ${ }^{20}$ verified that grain refinement was not observed until the fifth pass in an Al-Cu alloy containing $\theta$ ' particles. According to these authors, during the first pass the alloy hardness increases due to the work hardening, and after that the strain energy transferred to the sample is used for fracture, fragmentation or dissolution of the $\theta$ ' particles. 
Table 2. Rockwell B Hardness and tensile testing results of AA7050 Al alloy in the initial condition (before ECAP); and after ECAP at $423 \mathrm{~K}$ by Route A.

\begin{tabular}{|c|c|c|c|c|c|}
\hline San & ition & HRB [StDev] & $\begin{array}{l}\text { 0.2\% yield strength } \\
(\mathrm{MPa}) \text { [StDev] }\end{array}$ & $\begin{array}{c}\text { Ultimate strength } \\
\text { (MPa) [StDev] }\end{array}$ & $\begin{array}{c}\text { Elongation (\%) } \\
\text { [StDev] }\end{array}$ \\
\hline \multicolumn{2}{|c|}{ As received condition $\mathrm{T} 7451$} & $86.7[0.52]$ & $460[31]$ & $514[32]$ & $7.5[1.14]$ \\
\hline \multirow[t]{2}{*}{ ECAP } & 1 pass & $88.3[0.95]$ & $479[26]$ & $521[24]$ & $10.4[0.8]$ \\
\hline & 3 passes & $85.5[1.15]$ & - & - & - \\
\hline
\end{tabular}

Only after this stage the grain refinement takes place. The authors postulated then that the grain refinement is retarded in a two-phase alloy when compared to a single phase pressed by the same number of passes. The effect of second phase particles on grain refinement by ECAP was also discussed by Berta et al. ${ }^{31}$ that found that in the dispersoidscontaining alloy, coarse particles has been found to increase the rate of grain refinement and the homogeneity of the submicron grain structure. In contrast, the presence of fine particles inhibits the development of new high-angle grain boundaries and the formation of a fine grain structure. This behavior, according the authors, is believed to be caused by the dispersoids that homogenizes the slip and inhibits the formation of shear bands during deformation.

In this work, the sample in the initial over-aged condition, presented a large amount of small plate-like particles, but the morphology changed rapidly to a more equiaxial shape after ECAP. Besides that, the particle size become smaller after three passes what, as mentioned earlier, can be result of fragmentation. The refining grain size was observed, but it was less effective than that observed in the same alloy pressed by ECAP in the as-quenched condition under the same processing parameters. In this case, a pronounced grain refinement was observed already after the first pass ${ }^{27}$. Despite of the microstructural changes observed during ECAP, the mechanical properties showed only a slight increase after the first pass while after the third pass the hardness showed a decrease to values similar to that of initial condition. This mechanical behavior can be result of a balance between competing phenomena that are taking place during ECAP at $423 \mathrm{~K}$. On one hand the hardening effects, as grain size refining and work hardening imposed by the high stresses arising from ECAP, although the former effect can be retarded by fragmentation of particles as proposed by Murayama ${ }^{20}$ or inhibition of the formation of shear bands as proposed by Berta ${ }^{31}$. On the other hand, the softening effects caused by the use of a pressing temperature of $423 \mathrm{~K}$, are

\section{References}

1. Valiev RZ. Nanostructuring of metals by severe plastic deformation for advanced properties. Nature Materials. 2004; 3:511-516. PMid:15286754. http://dx.doi. org/10.1038/nmat1180

2. Valiev RZ and Langdon TG. Principles of equal-channel angular pressing as a processing tool for grain refinement. Progress in Materials Science. 2006; 51(7):881-981. http:// dx.doi.org/10.1016/j.pmatsci.2006.02.003

3. Horita Z, Fujinami T and Langdon TG. The potential for scaling ECAP: effect of sample size on grain refinement and mechanical properties. Materials Science and Engineering related to the recovery process and the increase in overaging due the dissolution of $\eta$ ' phase with consequent transformation to stable $\eta$ phase.

\section{Conclusions}

In the present work, the commercial AA7050 aluminum alloy in the overaged condition T7451, was processed by ECAP in order to assess the effects of process on the evolution of the microstructure of the alloy during pressing.

The microstructural changes during ECAP, represented by grain elongation, formation of deformation bands and elongated subgrains, with average width of $240 \mathrm{~nm}$, and high density of dislocations at their boundaries, was more significant after three passes. Despite the observed refining of microstructure, this seems to be less effective in the overaged alloy than in the as-quenched alloy, as observed in a previous work performed under the same processing conditions.

ECAP affects the size and morphology of particles. After the third pass the particle size tends to diminish and the morphology to be more spherical indicating fragmentation.

The major precipitated phase after ECAP is the $\eta$ phase, indicating additional overaging.

Concerning the mechanical properties, ECAP caused hardly any effect on tensile properties, while a slight increase in hardness was observed after one pass, with subsequent reduction after the third pass. This behavior can be result from a balance between competing phenomena: grain size refining and deformation hardening against softening by recovery and increasing over-aging.

\section{Acknowledgements}

The authors would like to acknowledge the financial support of FAPESP, process number 2005/03440-5.

A. 2001; 318(1-2):34-41. http://dx.doi.org/10.1016/S09215093(01)01339-9

4. Segal VM. Materials processing by simple shear. Materials Science and Engineering A. 1995; 197(2):157-164. http:// dx.doi.org/10.1016/0921-5093(95)09705-8

5. Iwahashi Y, Wang J, Horita Z, Nemoto M and Langdon TG. Principle of Equal-Channel Angular Pressing for the Processing of Ultra-Fine Grained Materials. Scripta Materialia. 1996; 35:143-146. http://dx.doi.org/10.1016/13596462(96)00107-8 
6. Djavanroodi F and Ebrahimi M. Effect of die channel angle, friction and back pressure in the equal channel angular pressing using 3D finite element simulation Materials Science and Engineering A. 2010; 527:1230-1235. http://dx.doi. org/10.1016/j.msea.2009.09.052

7. Gholinia A, Prangnell PB and Markushev MV. The Effect of Strain Path on the Development of Deformation Structures in Severely Deformed Aluminum Alloys Processed by ECAE. Acta Materialia. 2000; 48(5):1115-1130. http://dx.doi. org/10.1016/S1359-6454(99)00388-2

8. Furukawa M, Horita $\mathrm{Z}$ and Langdon TG. Processing by Equal-Channel Angular Pressing: Applications to Grain Boundary Engineering. Journal of Materials Science. 2005; 40:909-917. http://dx.doi.org/10.1007/s10853005-6509-0

9. Iwahashi $\mathrm{Y}$, Horita Z, Nemoto $\mathrm{M}$ and Langdon TG. An Investigation of Microstructural Evolution During Equal-Channel Angular Pressing. Acta Materialia. 1997; 45:4733-4741. http:// dx.doi.org/10.1016/S1359-6454(97)00100-6

10. Chinh NQ, Gubicza J, Czeppe T, Lendvai J, Xu C, Valiev RZ et al. Developing a strategy for the processing of age-hardenable alloys by ECAP at room temperature. Materials Science and Engineering A. 2009; 516:248-252. http://dx.doi. org/10.1016/j.msea.2009.03.049

11. Gubicza J, Schiler I, Chinh NQ, Illy J, Horita Z and Langdon TG. The effect of severe plastic deformation on precipitation in supersaturated $\mathrm{Al}-\mathrm{Zn}-\mathrm{Mg}$ alloys. Materials Science and Engineering A. 2007; 460-461:77-85. http://dx.doi. org/10.1016/j.msea.2007.01.001

12. Roshan MR, Jenabali Jahromi SA and Ebrahimi R. Predicting the critical pre-aging time in ECAP processing of age-hardenable aluminum alloys. Journal of Alloys and Compounds. 2011; 509:7833-7839. http://dx.doi.org/10.1016/j. jallcom.2011.05.025

13. Dadbakhsh S, Karimi Taheri A and Smith CW. Strengthening study on $6082 \mathrm{Al}$ alloy after combination of aging treatment and ECAP process. Materials Science and Engineering A. 2010; 527(18-19):4758-4766. http://dx.doi.org/10.1016/j. msea.2010.04.017

14. Zhao YH, Liao XZ, Jin Z, Valiev RZ and ZhuYT. Microstructures and mechanical properties of ultrafine grained $7075 \mathrm{Al}$ alloy processed by ECAP and their evolutions during annealing. Acta Materialia. 2004; 52:4589-4599. http://dx.doi.org/10.1016/j. actamat.2004.06.017

15. Sha G, Wang YB, Liao XZ, Duan ZC, Ringer SP and Langdon TG. Influence of Equal-Channel Angular Pressing on Precipitation in an Al-Zn-Mg-Cu Alloy. Acta Materialia. 2009; 57:3123-3132. http://dx.doi.org/10.1016/j. actamat.2009.03.017

16. Radetic T, Popovic M, Romhanji E and Velinden B. The effect of ECAP and $\mathrm{Cu}$ addition on the aging response and grain substructure evolution in an Al-4.4 wt.\% Mg alloy. Materials Science and Engineering A. 2010; 527(3):634-644.

17. Duan ZC, Chinh N Q, Xu C and Langdon TG. Developing processing routes for the equal-channel angular pressing of age-hardenable aluminum alloys. Metallurgical and Materials Transactions A. 2010; 41A(8):802-809. http://dx.doi. org/10.1007/s11661-009-0020-1

18. Cepeda-Jiménez CM, García-Infanta JM, Ruano OA and Carreño F. Mechanical properties at room temperature of an
$\mathrm{Al}-\mathrm{Zn}-\mathrm{Mg}-\mathrm{Cu}$ alloy processed by equal channel angular pressing. Journal of Alloys and Compounds. 2011; 509(35):8649-8656. http://dx.doi.org/10.1016/j.jallcom.2011.06.070

19. Liu Z, Bai S, Zhou X and Gu Y. On strain-induced dissolution of $\theta$ ' and $\theta$ particles in Al-Cu binary alloy during equal channel angular pressing. Materials Science and Engineering A. 2011; 528:2217-2222. http://dx.doi.org/10.1016/j. msea.2010.12.060

20. Murayama M, Horita $\mathrm{Z}$ and Hono K. Microstructure of two-phase Al-1.7 at\% $\mathrm{Cu}$ alloy deformed by equal-channel angular pressing. Acta Materialia. 2001; 49(1):21-29. http:// dx.doi.org/10.1016/S1359-6454(00)00308-6

21. Xu C, Furukawa M, Horita $Z$ and Langdon TG. Using ECAP to achieve grain refinement, precipitate fragmentation and high strain rate superplasticity in a spray-cast aluminum alloy. Acta Materialia. 2003; 51(20):6139-6149. http://dx.doi.org/10.1016/ S1359-6454(03)00433-6

22. Xu C, Furukawa M, Horita $\mathrm{Z}$ and Langdon TG. Influence of ECAP on precipitate distributions in a spray-cast aluminum alloy. Acta Materialia. 2005; 53(3):749-758. http://dx.doi. org/10.1016/j.actamat.2004.10.026

23. Driver JH. Stability of nanostructured metals and alloys. Scripta Materialia. 2004; 51(8):819-823. http://dx.doi.org/10.1016/j. scriptamat.2004.05.014

24. Oliveira Junior AF, Barros MC, Cardoso KR and Travessa DN. The effect of RRA on the strength and SCC resistance on AA7050 and AA7150 aluminium alloys. Materials Science and Engineering A. 2004; 379(1-2):321-326. http://dx.doi. org/10.1016/j.msea.2004.02.052

25. Zheng LJ, Li HX, Hashmi MF, Chen CQ, Zhang Y and Zeng MG. Evolution of microstructure and strengthening of 7050 Al alloy by ECAP combined with heat-treatment. Journal of Materials Processing Technology. 2006; 171:100-107. http:// dx.doi.org/10.1016/j.jmatprotec.2005.06.049

26. Zheng LJ, Chen CQ, Zhou TT, Liu PY and Zeng MG. Structure and properties of ultrafine-grained $\mathrm{Al}-\mathrm{Zn}-\mathrm{Mg}-\mathrm{Cu}$ and Al-Cu-Mg-Mn alloys fabricated by ECA pressing combined with thermal treatment. Materials Characterization. 2003; 49:455-461. http://dx.doi.org/10.1016/ S1044-5803(03)00069-X

27. Cardoso KR, Travessa DN, Botta WJ and Jorge Junior AM. High Strength AA7050 Al alloy processed by ECAP: Microstructure and mechanical properties. Materials Science and Engineering A. 2011; 528(18):5804-5811. http://dx.doi. org/10.1016/j.msea.2011.04.007

28. SAE International. Aerospace Material Specification $4050 \mathrm{H}$. SAE International; 2003.

29. Park JK and Ardell AJ. Microstructures of the commercial 7075 Al alloy in the T651 and T7 tempers. Metallurgical Transactions A. 1983; 14A:1957-1965. http://dx.doi. org/10.1007/BF02662363

30. Nam CY, Han JH, Chang YH and Shin MC. Effect of precipitates on microstructural evolution of $7050 \mathrm{Al}$ alloy sheet during equal channel angular rolling. Materials Science Engineering A. 2003; 347(1-2):253-257. http://dx.doi. org/10.1016/S0921-5093(02)00597-X

31. Berta M, Apps PJ and Prangnell PB. Effect of Processing Route and Second Phase Particles on Grain Refinement During ECAE. Materials Science and Engineering A. 2005; 410-411:381-385. http://dx.doi.org/10.1016/j.msea.2005.08.026 